\title{
THE INFLUENCE OF LEPTIN ON THE DEVELOPMENT OF IMMUNOLOGICAL DISORDERS IN PATIENTS WITH DIABETES MELLITUS TYPE 2 AND HYPOTHYROIDISM
}

\author{
Tatiana Yuzvenko
}

Department of prevention, treatment of diabetes mellitus, and its complications Ukrainian Scientifically and Practical Centre of Endocrine Surgery, Transplantation of Endocrine Organsand Tissues, Ministry of Public Health of Ukraine

13A Klovskiy descent, Kyiv, Ukraine, 01021

yuzvenko@bk.ru

Vladimir Pankiv

Department of prevention, treatment of diabetes mellitus, and its complications

Ukrainian Scientifically and Practical Centre of Endocrine Surgery, Transplantation

of Endocrine Organsand Tissues, Ministry of Public Health of Ukraine

13A Klovskiy descent, Kyiv, Ukraine, 01021

\begin{abstract}
The work deals with the determination of leptin and IL-6 influence on the development of immune disorders in patients with DM type 2 with hypothyroidism. There were examined 34 patients with diabetes mellitus type 2 and hypothyroidism and 27 patients with the primary hypothyroidism without DM. It was revealed that obesity is characterized with an increase of leptin and IL-6 levels that, in its turn, condition the development of system inflammation of the low intensity and result in the increase of risk of autoimmune changes. In patients with DM type 2 in combination with hypothyroidism on the background of obesity the indices of leptin, IL-6, CD4+, CD8+ and IRI reliably differed from the ones in the group of patients without obesity that testifies to the negative influence of obesity on the development of autoimmune immunological disorders in patients with DM type 2 . There were established the correlations between BMI and leptin and IL-6 CD4+, CD8+, IRI indices in patients with DM type 2 in combination with hypothyroidism.
\end{abstract}

Keywords: diabetes mellitus type 2, obesity, autoimmune diseases, hypothyroidism, leptin, interleukin-6.

\section{Introduction}

According to the modern views, diabetes mellitus (DM) type 2 is not autoimmune disease; its pathogenesis is based on the disorder of sensitivity to insulin [1]. But it is well-known, that metabolic disorders favor the disturbances in immune system, especially, in patients with DM type 2 takes place the metabolic immune suppression [2, 3].

Patients with DM type 2 are characterized with obesity (almost $90 \%$ ) that conditions the level of proinflammatory cytokines that complicate the existing immunologic disorders [4]. The proinflammatory cytokines are able to modulate immunological function through the several mechanisms which result is the disturbance of immune system that favor the autoimmune diseases that is why last years the significant attention of scientists was paid to the elucidation of the role of balance of proinflammatory cytokines in pathogenesis of autoimmune diseases $[5,6]$. The value of immune suppression as the main factor of development of concomitant autoimmune diseases in patients with DM type 2 is persuasively proved by the series of researches that demonstrated that support of the rigid metabolic control allows improve immunological changes [7]. The timely diagnostics of concomitant autoimmune diseases of thyroid gland (TG) in patients with DM type 2 and the further treatment are closely connected with the decrease of the risk of complications in the cardiovascular system and improvement of the life quality [8].

For today the role of adipocytokines, leptin and proinflammatory cytokines balance in the development of disorders in the immune system are actively studied [9-11]. Generally DM type 2 with concomitant obesity and immune imbalance has the common pathophysiological mechanisms that are the chronic activation of immune system. There was accented the role of rise of TNF- $\alpha$ (tumor necrosis factor- $\alpha$ ), Il-1 $\beta$ (interleukin-1 $\beta$ ), IL-6 (interleukin-6), leptin content and decrease 
of proinflammatory signal molecules that result in immune imbalance, including autoimmune pathology [12-14].

For today the role of leptin in the development of autoimmune diseases is not finally established [15]. There was detected the leptin ability to stimulate the cellular immune response and also its influence on phagocytic activity of macrophages with an increase of production of proinflammatory cytokines [16]. The numerous prospective cohort studies proved the dependence between the concentrations of interleukin-6 (IL-6), mass of fatty tissue and insulin resistance (IR). It is known, that IL-6 has proinflammatory effect and influence the carbohydrate metabolism [17]. The value of immune suppression as the main factor of development of concomitant autoimmune diseases in patients with DM type 2 was persuasively proved by the series of researches that demonstrated that support of the rigid metabolic control allows improve immunological changes [18]. In most cases DM type 2 is combined with abdominal-visceral obesity [19]. The direct connection was demonstrated between the obesity degree and speed of development of manifestations and complications of DM type 2 [20]. That is why the treatment of patients with diabetes mellitus (DM) type 2 and concomitant primary hypothyroidism must be directed on both compensation of metabolic disorders and normalization of changes in immune system [21].

\section{Aim of research}

Determination of the leptin and IL-contribution in the development of immune disorders in patients with DM type 2 and hypothyroidism.

\section{Materials and methods}

The work is carried out on the base of department prophylaxis and treatment of diabetes mellitus in Ukrainian scientific-practical centre of endocrine surgery, transplantation of endocrine tissues and organs of MHP of Ukraine.

The groups of patients with DM type 2 and hypothyroidism $(n=34)$ and with primary hypothyroidism without DM ( $\mathrm{n}=27)$ were under observation. Patients with severe concomitant pathology and heavy complications of the main disease that could have an influence on the indices of research were not included in the studied groups.

The duration of DM and hypothyroidism was assessed according to the data of life and disease anamnesis and also according to the ambulatory case records of patients. Diagnosis diabetes mellitus was set on the WHO criteria of 1999. All patients underwent the complex clinical examination taking into account complaints, anamnesis data (including family anamnesis: detection of the inherent inclination to DM, TG diseases, obesity; social anamnesis: feature of life style, food and harmful habits); objective (survey, palpation, percussion, auscultation) and additional (clinical, biochemical, immunological, hormonal and instrumental) methods of research. In patients were assessed the data of hormonal thyroid status on the levels of TTG, free thyroxin $\left(\mathrm{fT}_{4}\right)$, free triiodothyronine $\left(\mathrm{fT}_{3}\right.$ ), immune status by the determination of antibodies to the thyroid peroxidase (TPO). The glucose concentration in blood was determined by colorimetric method on automatic biochemical analyzer Sapphire-400, Tokio Boek L.T.D. Elitech diagnostics made by Seppin S.A.S. (France). The determination of glycated hemoglobin (HbAlc) concentration in blood was carried out by the method of high sensitive ion exchange liquid chromatography using automatic analyzed D-10 of BIORAD (USA) with the help of reagent D-10 Hemoglobin Testing System, Dual Program Recorder Pack (France). Assessment of the cellular link (Tx, cytotoxic lymphocytes level, immune regular index (Tx/cytotoxic lymphocytes) was based on the principle of markerogenic identification of sheep erythrocytes on the base of complementarity [6]. For studying the status of immune system of patients with DM in combination with hypothyroidism by immune peroxidase method using monoclinic antibodies was studied the content of lymphocytes subpopulation in peripheral blood (percentage content: T-lymphocytes (CD3+ - general T-lymphocytes, CD4+ - Tx, CD8 - cytotoxic lympocytes), CD20+ lymphocytes ( $\beta$-cells), NK-cells (CD16+) and proinflammaory cytokine concentration - IL-4. Erythrocytic diagnostics of detection of T- and B-lymphocytes subpopulation was carried out by the sets of LD SPL "Granum" (Kharkiv city, 
Ukraine) using the reaction of rosette creation with erythrocytes which the monoclonal antibodies were adsorbed on (measurement diapason- 0-100\%; norm for CD3+ - 50-80\%, $\mathrm{CD} 4+-33-46 \%, \mathrm{CD} 8+-17-30 \%, \mathrm{CD} 20+-11-16 \%, \mathrm{CD} 22+-17-31 \%, \mathrm{CD} 16+-12-23 \%$, CD95+- 10-30\%). There was also studied the concentration of soluble form of Fas-receptor (CD95+) in blood serum [7]. Using immunosorbent method on «StatFax» analyzer were studied the IL-6 and leptin levels. IL-6 level was determined by quantitative method by the sets of reagents Pro Con IL-6 (St-Petersburg city, Russia) which principle is in the use of "Sandwich" variant of immunosorbent analysis with mono- and polyclonal antibodies (measurement diapason - (0-250) pg/ml; norm - (0-10) pg/ml).

Statistical analysis included descriptive statistics, check of the character of indices distribution. The significance of differences was evaluated on the Student's criterion $(t)$ for the normal sings distribution. The differences with reliability level less than 0,05 were assessed as clinically significant ones. All statistical calculations were carried out at the significance level $95 \%(p=0,05)$. At the distribution that differs from the normal one was used nonparametric method of calculationU-Mann-Whitney criterion for two independent samples. The received data were present in the table ant text as relative ones, values - $(\%)$, and also as $(M \pm m)$, where $M-$ arithmetical mean value, $\mathrm{m}$ - standard mean error, Me [25, 75] (Me - median 25-th and 75-th quartiles). The differences were considered as statistically significant at $\mathrm{p}<0,05$.

\section{Results}

Patients with DM type 2 with hypothyroidism were from the older age group, had the reliable increase of BMI indices ( $\mathrm{p}<0,001$ ) comparing with patient with DM without hypothyroidism. The BMI rise was conditioned by abdominal obesity according to WS/HS indices. At abdominal obesity takes place the cytokines imbalance toward the rise of activity of proinflammatory cytokines that supports the chronic inflammation of the low intensity. With age the content of fatty tissues increases and also raises the resistance to leptin and as the result its level increases.

For the moment of examination carbohydrate metabolism in all patients was at the stage of decompensation. The mean $\mathrm{HbA}_{1 \mathrm{c}}$ level was $-7,8 \%$, mean daily glycemia $-9,2 \mathrm{mmol} / \mathrm{l}$ in patients with DM type 2 in combination with hypothyroidism. In patients with DM lipidogram indices were significantly higher than in patients with DM type 2 in combination with hypothyroidism comparing with patients with DM type 2 without hypothyroidism $(\mathrm{p}<0,001)$.

In patients with DM type 2 in combination with hypothyroidism on the background of obesity the indices of leptin IL-6, CD4+, CD8+ and IRI reliably differed from the ones in the group of patients without obesity that indicates the negative influence of obesity on the development of autoimmune immunological disorders in patients with DM type 2 that can also favor the chronic inflammation.

Median of the leptin level in examined patients with DM type 2 with hypothyroidism was $32,1 \mathrm{pg} / \mathrm{ml}$ that exceeded norm in more than 2 times and IL-6 level was $22,7 \mathrm{pg} / \mathrm{ml}$ that also exceeded norm almost twice (referent values $0-10 \mathrm{pg} / \mathrm{ml}$ ). At comparative analysis in the groups of examined patients was established that leptin and IL-6 levels were reliably higher in patients with DM type 2 with hypothyroidism on the background of obesity than in the group of patients with DM type 2 without obesity $(p<0,05)$. Median of CD4+ level in patients with DM type 2 with hypothyroidism was 4,6, CD8+, CD12+, at the same time the CD8+, lymphocyte-suppressor level was significantly lower comparing with patients with DM type 2 without obesity that proves the expressed immune suppression conditioned by the chronic inflammation and metabolic changes. In its turn, in patients with DM type 2 with hypothyroidism IRI median was significantly higher $-4,9$.

We also detected the correlations between BMI and leptin and IL-6, CD4+, CD8+, IRI indices in patients with DM type 2 combined with hypothyroidism (Table 1).

The researches revealed that leptin and IL-6 levels had a negative correlation with CD8+T-cells-suppressors and positive one with CD4+ that has a significant value in pathogenesis of autoimmune diseases. It was proved, that leptin and IL-6 levels had a positive correlation with BMI. 
Table 1

Coefficients of correlation of IL-6 and liptin with T-cellular link of immunity and BMI

\begin{tabular}{|c|c|c|c|c|c|c|c|c|}
\hline \multirow{2}{*}{ Index } & \multicolumn{2}{|c|}{ BMI } & \multicolumn{2}{|c|}{ CD4+, \% } & \multicolumn{2}{|c|}{ CD8+, \% } & \multicolumn{2}{|c|}{ IRI } \\
\hline & $\mathbf{r}_{\mathrm{s}}$ & $\mathbf{p}$ & $\mathbf{r}_{\mathrm{s}}$ & $\mathbf{p}$ & $\mathbf{r}_{\mathrm{s}}$ & $\mathbf{p}$ & $\mathbf{r}_{\mathrm{s}}$ & $\mathbf{p}$ \\
\hline \multicolumn{9}{|c|}{ DM type 2 with hypothyroidism } \\
\hline Leptin & 0,82 & $\mathrm{p}<0,05$ & 0,83 & $\mathrm{p}<0,05$ & 0,87 & $\mathrm{p}<0,05$ & 0,8 & $\mathrm{p}<0,01$ \\
\hline IL-6 & 0,91 & $\mathrm{p}<0,001$ & 0,87 & $\mathrm{p}<0,05$ & $-0,8$ & $\mathrm{p}<0,01$ & 0,92 & $\mathrm{p}<0,01$ \\
\hline \multicolumn{9}{|c|}{ DM type 2 without hypothyroidism } \\
\hline Leptin & 0,76 & $\mathrm{p}<0,01$ & 0,68 & $\mathrm{p}<0,05$ & $-0,52$ & $\mathrm{p}<0,05$ & 0,51 & $\mathrm{p}<0,05$ \\
\hline IL-6 & 0,67 & $\mathrm{p}<0,05$ & 0,53 & $\mathrm{p}<0,05$ & $-0,63$ & $\mathrm{p}<0,05$ & 0,62 & $\mathrm{p}<0,05$ \\
\hline
\end{tabular}

Notes: $r_{s}$ - rank coefficient of Spearman correlation; $p$ - significance of indices differences

\section{Discussion}

Metabolic changes revealed in patients with DM type 2 and hypothyroidism in the further can deepen the shifts of immune status namely metabolic immune suppression that is characterized with decrease of CD8+ - cells level on which expense IRI increases that results in development and progressing of autoimmune disorders.

Our results correspond to the ones of other authors [7, 11].

Obesity is characterized with an increase of leptin and IL-6 levels that, in their turn, condition the development of system inflammation of low intensity and result in the rise of risk of autoimmune changes development.

Taking into account the significant spread of DM, especially, type 2 and also autoimmune diseases in population for the last decade and the tendency to world population aging, the combination of DM type 2 with hypothyroidism is quite frequent $[4,19]$. It is also important that mechanisms that participate in the lesion of organs and tissues in patients with DM type 2 are rather complicated but most likely they are based on both metabolic and immunological changes. At hyperglycemia many factors that in the normal state regulate the tissue homeostasis are intensified. It must be underlined that the aforesaid disorders are not specific for diabetes mellitus because they are very frequent at various lesions of inflammatory and degenerative character. In patients with DM these disorders are complicated with hyperglycemia and the other biochemical disturbances that appear on its background. The significance of hyperglycemia as one of the risk factors of autoimmune disorders in patients with DM was demonstrated in several researches that proved that the support of rigid metabolic control allows normalize the immunological changes.

At the same time at metabolic-immunological changes prescription of preparations that influence the pathogenetic mechanisms of the destructive processes development is needed.

That is why we offer to study the content of lymphocyte subpopulation in peripheral blood and calculate the immune regulatory index for prognostication of development and progressing of existing concomitant autoimmune diseases in patients with diabetes mellitus type 2 .

The limitation of our research is in the insufficient number of examined. At the same time in the article is firstly considered the role of metabolic shifts and cytokine imbalance in the further development and progressing of autoimmune processes in patients with DM type 2 combined with hypothyroidism.

\section{Conclusions}

There was established statistically significant increase of leptin and IL-6 levels in patients with DM type 2 and hypothyroidism at the reliable increase of lipid metabolism indices that testifies to the metabolic immune suppression in conditions of cytokine imbalance.

1. Leptin and IL-6 level in examined patients with DM type 2 and hypothyroidism exceeded the normal ones more than twice.

2. There was revealed the clear positive interconnection between the leptin and IL- 6 levels in patients with DM type 2 at obesity and the degree of the immune system activity.

3. In patients with DM type 2 with hypothyroidism were detected immunological changes that in the further favor the development of autoimmune diseases. 


\section{References}

[1] Garber, J., Cobin, R., Gharib, H., Hennessey, J., Klein, I., Mechanick, J. et. al (2012). Clinical Practice Guidelines for Hypothyroidism in Adults: Cosponsored by the American Association of Clinical Endocrinologists and the American Thyroid Association. Endocrine Practice, 18 (6), 988-1028. doi: 10.4158/ep12280.gl

[2] Singh, G. M., Danaei, G., Farzadfar, F., Stevens, G. A., Woodward, M., Wormser, D. et. al (2013). The Age-Specific Quantitative Effects of Metabolic Risk Factors on Cardiovascular Diseases and Diabetes: A Pooled Analysis. PLoS ONE, 8 (7), e65174. doi: 10.1371/journal.pone.0065174

[3] Hennessey, J. V., Espaillat, R. (2015). Diagnosis and Management of Subclinical Hypothyroidism in Elderly Adults: A Review of the Literature. Journal of the American Geriatrics Society, 63 (8), 1663-1673. doi: 10.1111/jgs.13532

[4] Berrington de Gonzalez, A., Hartge, P., Cerhan, J. R., Flint, A. J., Hannan, L., MacInnis, R. J. et. al (2010). Body-Mass Index and Mortality among 1.46 Million White Adults. New England Journal of Medicine, 363(23), 2211-2219. doi: 10.1056/nejmoa1000367

[5] Johnson, J. L. (2006). Diabetes Control in Thyroid Disease. Diabetes Spectrum, 19 (3), 148-153. doi: 10.2337/diaspect.19.3.148

[6] Man'kovskij, B. N. (2014). Rasprostranennost' nevyjavlennogo saharnogo diabeta 2 tipa i prediabeta v Ukraine: rezul'taty jepidemiologicheskogo issledovanija «DIAPAZON». Diabet. Ozhirenie. Metabolicheskij sindrom, 3 (5), 70-75.

[7] Global status report on noncommunicable diseases 2014 (2014). WHO. Geneva: World Health Organization, 298.

[8] Zheng, W., McLerran, D. F., Rolland, B., Zhang, X., Inoue, M., Matsuo, K. et. al (2011). Association between Body-Mass Index and Risk of Death in More Than 1 Million Asians. New England Journal of Medicine, 364 (8), 719-729. doi: 10.1056/nejmoa1010679

[9] The Emerging Risk Factors Collaboration (2011). Separate and combined associations of bodymass index and abdominal adiposity with cardiovascular disease: collaborative analysis of 58 prospective studies. The Lancet, 377 (9771), 1085-1095. doi: 10.1016/s0140-6736(11)60105-0

[10] Metabolic mediators of the effects of body-mass index, overweight, and obesity on coronary heart disease and stroke: a pooled analysis of 97 prospective cohorts with 1.8 million participants (2014). The Lancet, 383 (9921), 970-983. doi: 10.1016/s0140-6736(13)61836-x

[11] Ng, M., Fleming, T., Robinson, M., Thomson, B., Graetz, N., Margono, C. et. al (2014). Global, regional, and national prevalence of overweight and obesity in children and adults during 1980-2013: a systematic analysis for the Global Burden of Disease Study 2013. The Lancet, 384 (9945), 766-781. doi: 10.1016/s0140-6736(14)60460-8

[12] Stevens, G. A., Singh, G. M., Lu, Y., Danaei, G., Lin, J. K., Finucane, M. M. et. al (2012). National, regional, and global trends in adult overweight and obesity prevalences. Population Health Metrics, 10 (1), 22. doi: 10.1186/1478-7954-10-22

[13] Kitahara, C. M., Flint, A. J., Berrington de Gonzalez, A., Bernstein, L., Brotzman, M., MacInnis, R. J. et. al (2014). Association between Class III Obesity (BMI of 40-59 kg/m2) and Mortality: A Pooled Analysis of 20 Prospective Studies. PLoS Medicine, 11 (7), e1001673. doi: 10.1371/journal.pmed.1001673

[14] Han, Z., Mulla, S., Beyene, J., Liao, G., McDonald, S. D. (2010). Maternal underweight and the risk of preterm birth and low birth weight: a systematic review and meta-analyses. International Journal of Epidemiology, 40 (1), 65-101. doi: 10.1093/ije/dyq195

[15] Danaei, G., Finucane, M. M., Lin, J. K., Singh, G. M., Paciorek, C. J., Cowan, M. J. et. al (2011). National, regional, and global trends in systolic blood pressure since 1980: systematic analysis of health examination surveys and epidemiological studies with 786 country-years and 5.4 million participants. The Lancet, 377 (9765), 568-577. doi: 10.1016/s0140-6736(10)62036-3

[16] Danaei, G., Singh, G. M., Paciorek, C. J., Lin, J. K., Cowan, M. J., Finucane, M. M. et. al (2013). The Global Cardiovascular Risk Transition: Associations of Four Metabolic Risk Factors with National Income, Urbanization, and Western Diet in 1980 and 2008. Circulation, 127 (14), 1493-1502. doi: 10.1161/circulationaha.113.001470

[17] Ezzati, M., Riboli, E. (2013). Behavioral and Dietary Risk Factors for Noncommunicable Diseases. New England Journal of Medicine, 369(10), 954-964. doi:10.1056/nejmra1203528

[18] Huxley, R., Mendis, S., Zheleznyakov, E., Reddy, S., Chan, J. (2009). Body mass index, waist circumference and waist:hip ratio as predictors of cardiovascular risk - a review of the literature. European Journal of Clinical Nutrition, 64 (1), 16-22. doi: 10.1038/ejen.2009.68 
[19] Pednekar, M. S., Hakama, M., Hebert, J. R., Gupta, P. C. (2008). Association of body mass index with all-cause and cause-specific mortality: findings from a prospective cohort study in Mumbai (Bombay), India. International Journal of Epidemiology, 37 (3), 524-535. doi: 10.1093/ije/dyn001

[20] Di Cesare, M., Bennett, J. E., Best, N., Stevens, G. A., Danaei, G., Ezzati, M. (2013). The contributions of risk factor trends to cardiometabolic mortality decline in 26 industrialized countries. International Journal of Epidemiology, 42 (3), 838-848. doi: 10.1093/ije/dyt063

[21] Ezzati, M., Riboli, E. (2012). Can Noncommunicable Diseases Be Prevented? Lessons from Studies of Populations and Individuals. Science, 337 (6101), 1482-1487. doi: 10.1126/science.1227001

\title{
RESECTION OPERATIONS IN SURGICAL TREATMENT OF PATIENTS WITH CHRONIC PANCREATITIS COMPLICATED BY BILIARY HYPERTENSION
}

\author{
Volodymyr Pylypchuk \\ Department of surgery of the Institute of Postgraduate \\ Education of the Ivano-Frankivsk National Medical University \\ 91 Fedkovycha str., Ivano-Frankivsk, Ukraine, 76000 \\ vipdoz@ukr.net \\ Andriy Yavorskyy \\ Ivano-Frankivsk Regional Clinical Hospital \\ Ivano-Frankivsk National Medical University \\ 91 Fedkovycha str., Ivano-Frankivsk, Ukraine, 76000 \\ burg555@mail.ru \\ Galyna Shabat \\ National Cancer Institute of Ukraine \\ 33/43 Lomonosova str., Kyiv, Ukraine, 03022 \\ galyna.shabat@gmail.com \\ Marino Marco Vito \\ Department of Surgery \\ Europen Institute of Oncology, Milan, Italy \\ 435 Giuseppe Ripamonti str., Milan, Italy, 20141 \\ marco.vito.marino@gmail.com
}

\begin{abstract}
Surgical treatment was applied in 145 patients with complicated forms of chronic pancreatitis (CP) at the department of surgery of the Ivano-Frankivsk Regional Clinical Hospital in 2009-2016. Fourty-nine (33.7 \%) patients had symptoms of biliary hypertension (BH); in five (3.4\%) of them BH was combined with chronic duodenal obstruction (CDO), the other $5(3.4 \%)$ patients had a combination of BH+C$\mathrm{DP}$ and local venous hypertension of pancreaticobiliary area vessels. Resection-type surgeries were applied in 28 (57.1\%) patients with CP complicated by BH. Intraoperative monitoring of biliary pressure was used in 17 patients in the process of duodenum-preserving resections of the pancreas. Frey's procedure was applied to 20 (71.4 \%) patients, in whom BH persisted after the resection stage of the surgery; Frey's procedure was supplemented by interventions on bile ducts: hepaticoenteroanastomosis was applied in 12 patients, excision of pancreas lingula was applied in one patient, internal biliopancreatic anastomosis was applied in one patient. Berne modification was used in 2 (7.2 \%) patients, and pancreaticoduodenal resection (PDR) according to Whipple - in 6 (21.4\%) patients. Remote results were studied in 19 (67.8 \%) patients. Patients after duodenum-preserving resections had the best quality of life indicators, for BH signs were absent.

Keywords: chronic pancreatitis, biliary hypertension, duodenum-preserving resection, biliary pressure, pancreatic-duodenal resection.
\end{abstract}

